\title{
New Leakage Current Particulate Matter Sensor for On-Board Diagnostics
}

\author{
Jiawei Wang, ${ }^{1}$ Dong Tang, ${ }^{1}$ Songhua Wang, ${ }^{1}$ Zehong Zhu, ${ }^{1}$ Nan Li, ${ }^{1}$ and Lie Chen ${ }^{2}$ \\ ${ }^{1}$ Department of Automotive and Traffic Engineering, Jiangsu University, Zhenjiang 212013, China \\ ${ }^{2}$ Jintan Jonssen Electric-Tech Corp, Changzhou 213200, China \\ Correspondence should be addressed to Dong Tang; dtang@mail.ujs.edu.cn
}

Received 22 May 2016; Accepted 2 August 2016

Academic Editor: Yan Lu

Copyright (c) 2016 Jiawei Wang et al. This is an open access article distributed under the Creative Commons Attribution License, which permits unrestricted use, distribution, and reproduction in any medium, provided the original work is properly cited.

\begin{abstract}
Structure and principle of the new leakage current particulate matter (PM) sensor are introduced and further study is performed on the PM sensor with the combination of numerical simulation and bench test. High voltage electrode, conductive shell, and heaters are all built-in. Based on the principle of Venturi tube and maze structure design, this sensor can detect transient PM concentrations. Internal flow field of the sensor and distribution condition of PM inside the sensor are analyzed through gas-solid two-phase flow numerical simulation. The experiment was also carried out on the whole sensor system (including mechanical and electronic circuit part) and the output signals were analyzed. The results of simulation and experiment reveal the possibility of PM concentration (mass) detection by the sensor.
\end{abstract}

\section{Introduction}

Energy saving and environmental protection have always been the hot and difficult problems in the research field of internal combustion engine. Diesel engine is widely used in industry, agriculture, construction, transportation, and other domains because of its low fuel consumption, high thermal efficiency, reliability, and low $\mathrm{CO}_{2}$ emission. But the high PM emission of diesel engine will have great influence on human health and environment $[1,2]$. Diesel particulate filters (DPF) have been widely used in diesel vehicles to remove PM from exhaust gas and help meet stringent legislation [35]. On-board diagnostics (OBD) require monitoring of the DPF system for malfunction that may cause PM emission to exceed the regulated levels. In order to fulfill future OBD legislations, which include more stringent requirements on monitoring the functionality of those particulate filters, new sensors which can measure PM concentration directly and withstand harsh exhaust gas environment are necessary for OBD purposes [6]. The stringent emission limit of PM is illustrated in Table 1.

Several technologies of PM detection have been so far proposed such as insulator-based devices which generate large change in electrical resistance or capacitance with the deposition of PM over the insulating layer $[7,8]$ and catalytic combustion method which converts the heat generated by the catalytic combustion of soot (C) and soluble organic fraction (SOF) into electrical signal separately [9]. Enterprises such as $\mathrm{BOSCH}$ and NTK are carrying out research on PM sensor $[10,11]$. The sensors designed by BOSCH and NTK are based on insulator-based devices and measuring electrical capacitance and resistance over the insulating layer, respectively. But resolution of the two sensors is not too high which cannot meet the requirement of instantaneous concentration measurement of PM [12].

In this study, a real-time electronic device based on leakage current was proposed as a PM sensor [13]. Differing with other kinds of PM sensors, this kind of sensor has a conductive shell which is connected to ground and electrodes which are applied with a high voltage. When the exhaust gas flows through the gap between the high voltage electrode and conductive shell, PM inside the gas will be ionized and polarized into conductors, while it has no influence on other substances such as water vapor and carbon dioxide. Then leakage current will be produced between electrode and conductive shell. The PM concentration is obtained based 
TABLE 1: The emission limits of PM for automotive compression ignition engine.

\begin{tabular}{lccc} 
& $\begin{array}{c}\text { Euro-VI PM emissions } \\
\text { limit }\end{array}$ & OBD-I threshold & OBD-II threshold \\
\hline PM (mass) & $4.5 \mathrm{mg} / \mathrm{km}\left(3.33 \mathrm{mg} / \mathrm{m}^{3}\right)$ & $20 \mathrm{mg} / \mathrm{km}\left(14.8 \mathrm{mg} / \mathrm{m}^{3}\right)$ & $9 \mathrm{mg} / \mathrm{km}\left(6.7 \mathrm{mg} / \mathrm{m}^{3}\right)$ \\
PN (count) & $6 \times 10^{11}$ & Requirements postponed for lack of adequate sensing technology \\
\hline
\end{tabular}

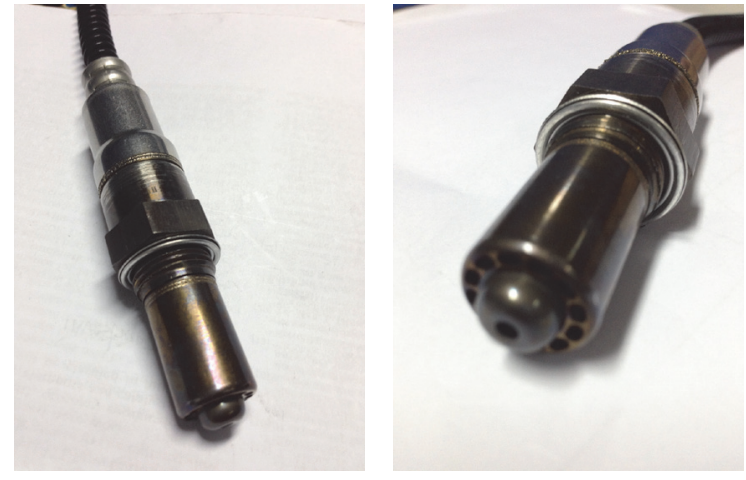

FIGURE 1: Appearance of proposed leakage current PM sensor.

on the functional relationship between leakage current and PM concentration. When the PM concentration gets higher, the emission dielectric constant will also become bigger, which increases the leakage current. On the contrary, lower PM concentration decreases the leakage current. The control system in PM sensor can transform the leakage current signal into voltage signal to make signal processing convenient. After some interval of time, the heater will start to burn off the accumulated PM, which will influence output signals of the sensor [14, 15]. And gas-solid two-phase flow numerical simulation was carried out to analyze the flow of gas phase and particle phase inside the sensor [16-19]. Then bench test was performed on the whole sensor system (including mechanical and electronic circuit part) and output signals of the sensor were analyzed.

The results of simulation and experiment have guidance function for further design of the senor and they reveal the possibility of PM detection by the leakage current PM sensor.

\section{Sensor Introduction}

The appearance of proposed leakage current PM sensor is shown in Figure 1. Subassembly of the sensor can be seen in Figure 2. Part 1 consists of the conductive shell, annular flow guide, and high voltage electrode. Parts 2, 3, and 4 are the heater, the insolated, and sealed section and the sensorharness interconnect and environmental seals, respectively, while part 5 is electronic circuits and its housing.

2.1. Sensor Calibration. A PM sensor calibration system is adopted to calibrate the initial condition of the sensor: fuel is introduced into an inverse diffusion flame combustor which is connected with an exhaust pipe. Then the gas mixture is ignited and produces stable soot. After that, a compressor is started and introduces a stable quantity of air which can be adjusted through a pressure-regulating valve and heated by a heater. The air enters the exhaust pipe to dilute the soot produced by combustion and the air input flow is read by a flowmeter. At the same time, a temperature sensor outputs the temperature of diluted particles. When the soot enters the sensor, a current signal is output and then amplified and converted by a circuit board; then a voltage signal is output. The signal value is acquired by an A/D converter and read by a computer. A transient smokemeter is started in the moment when the soot enters the sensor, and transient soot concentration is measured and output. The voltage values outputs by the PM sensor under different soot concentrations are recorded, a calibration curve representing the changes of the voltage values is drafted, and accurate particle concentration is obtained.

2.2. Measuring Methods. It can be seen from Figure 3 that the arrow direction represents the gas flow path. Because of the design based on Venturi tube principle, the pressure at the head of the sensor is low. So there is an adsorption forcing the gas flow inside the sensor. The conductive shell is connected to ground, and high voltage is applied to the high voltage electrode, which is about $800 \sim 1000 \mathrm{~V}$. When exhaust gas flows through the gap between the high voltage electrode and conductive shell, PM will be ionized and polarized into conductors, while it has no influence on other substances such as water vapor and $\mathrm{CO}_{2}$. Then leakage current will be produced between electrode and conductive shell. The PM concentration is obtained based on the functional relationship between leakage current and PM concentration.

2.3. High Voltage Generation and Signal Processing. The leakage current sensor investigated in this paper consists of mechanical part and electronic circuit. The mechanical part of the sensor mainly includes electrode and $1000 \mathrm{~V}$ power (the design of $1000 \mathrm{~V}$ power could meet the design requirement after experimental verification in the report of Emisense Company). One side of the electrode is connected to the positive of the $1000 \mathrm{~V}$ power and the other side to the operational amplifier of the electronic circuit. The design requirement of the control system in PM sensor is to transform the leakage current signal, which varies with the change of PM concentration, into voltage signal. The signal should be filtered, amplified, calibrated, amended, A/D converted, and so forth. And then it should be transformed into controller area network (CAN) telegram information through CAN controller integrated in the single chip microcomputer. Finally it is connected into the BUS by CAN transceiver [20].

Figure 4 indicates the electronic circuitry of leakage current PM sensor. The electronic circuit consists of signal amplification circuit, module of single chip microcomputer, 


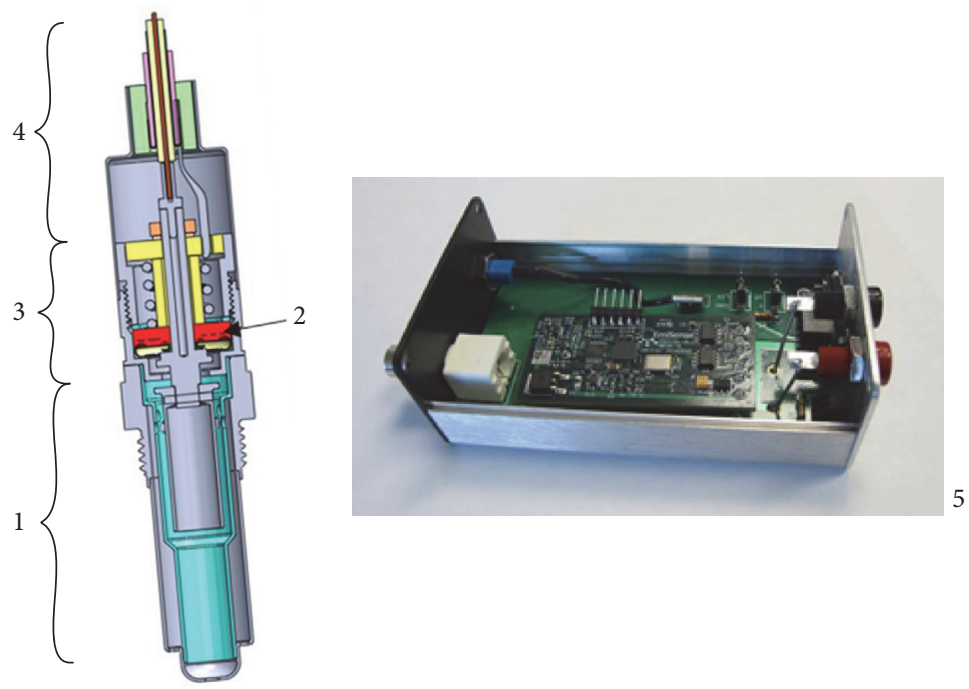

FIGURE 2: Subassembly of leakage current sensor.

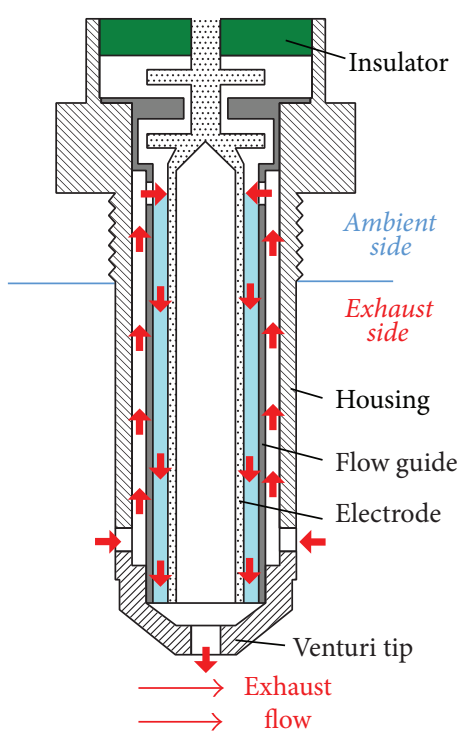

FIGURE 3: Flow drawing based on the principle of Venturi tube.

CAN transceiver, heating module, temperature measuring module, and power module.

2.4. Sensor Regeneration and Maze Design. Due to small size of sensor structure, the gap between high voltage electrode and conductive shell, heater, and lead wires cannot be set big enough. Therefore, PM is accumulated in all gaps some time later, and the leakage current will increase. The PM sensor cannot work normally when accumulated PM reaches a certain thickness. So a heater consists of exothermic ceramics, and positive and negative electrodes are integrated in the sealed space. The exothermic ceramics is closing to the side of exhaust flow space, and the negative electrode is connected to the ground. In the exothermic ceramics, positive and negative electrodes are coated with insulating and high temperature resistance ceramic shielded layer. With PM accumulated, resistance between the metal shielded layer and conductive shell will decrease, which can be used as a judgment signal. When the resistance is lesser than the programmed value, the heater is started by the resistance controlling circuit and then the accumulated PM is burned off by electricity discharged by the high voltage electrode. In addition, though a heater is needed to burn off the accumulated PM, the excessive energy consumption can be ignored comparing to the total consumption.

To decrease the amount of PM flowing into the sealed space, maze structure is designed in front of the sealed space [21]. The maze design consists of two shoulders which can be seen in Figure 5. The mutually staggered two shoulders are designed between the shell and electrode. The first shoulder is set in the flow space of exhaust and integrated with the electrode, and the second one is set on baffle ring which connected firmly to the shell. The two shoulders formed several curves, which can reduce the amount of PM flowing into the sealed space and the effect of maze structure design can be seen in the numerical simulation part.

\section{Numerical Simulation and Analysis}

Since the inner structure of the PM sensor is complex, it is difficult to get the distribution condition of its inner flow field and PM. With the quick development of simulating calculation, it is available to use computational fluid dynamics (CFD) to simulate flow process inside the sensor and obtain various parameters of gas and PM which can be used to optimize structure of the PM sensor. The models of $k-\varepsilon$ and DPM are adopted for the gas phase and disperse phase, respectively, while the SIMPLE model of gas-solid two phase flow is used for the numerical simulation. Three-dimension and mesh model of the PM sensor can be seen in Figure 6. 


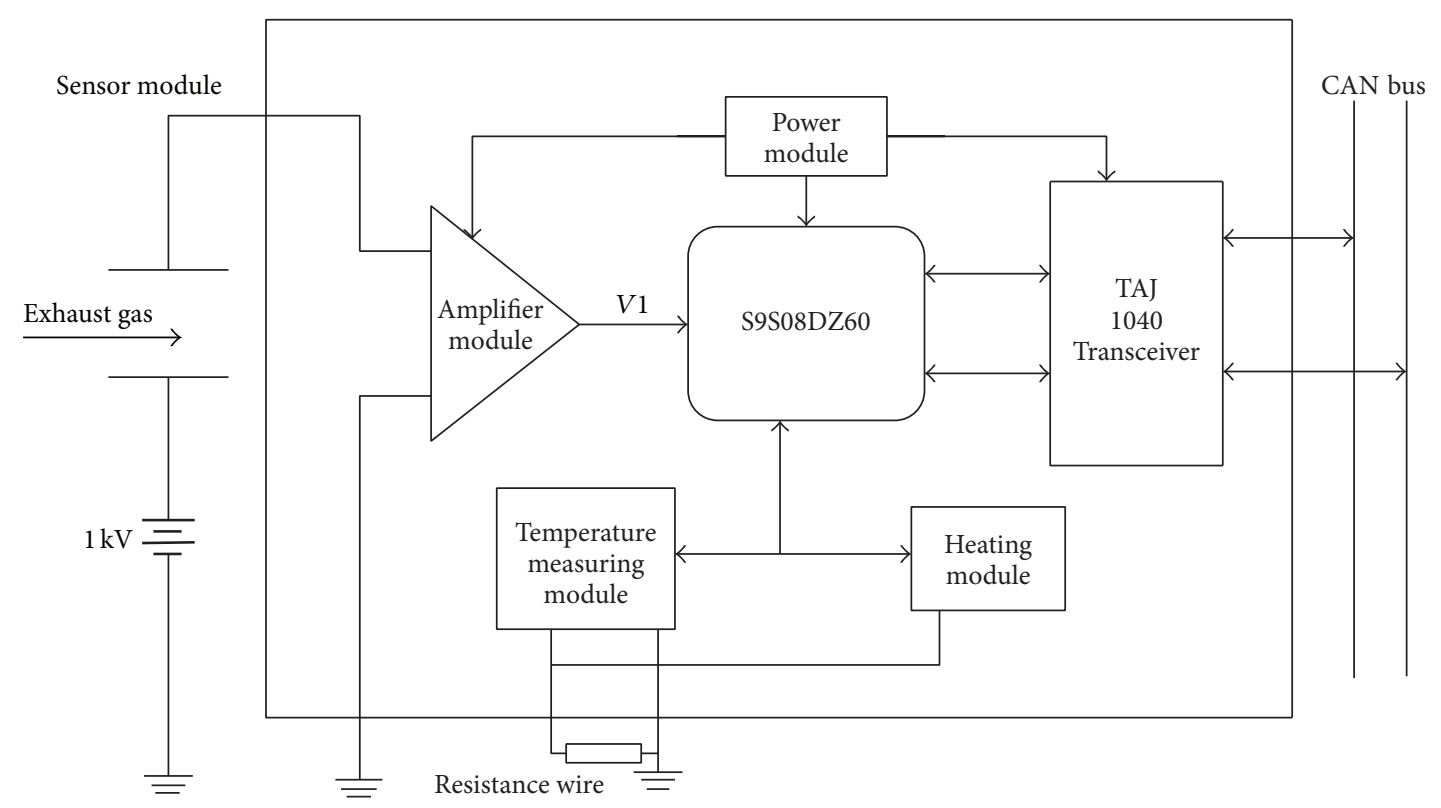

FIGURE 4: Electronic circuitry of leakage current PM sensor.

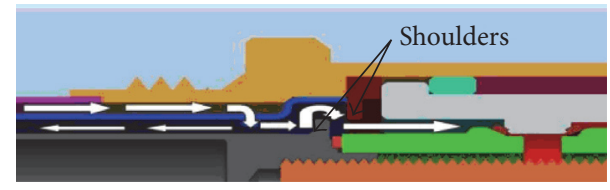

FIGURE 5: Maze design structure drawing.

3.1. Velocity Distribution. Figure 7 shows the velocity distribution of $z=0$ section. It can be seen that flow rate of exhaust gas in the concentration testing area is steady, and there is an obvious velocity gradient distribution at the head of the sensor. Flow rate is gradually accelerated due to its small sectional area. On the other hand, the flow rate of exhaust gas in the space of maze design and central cavity is low.

Figure 9 shows the velocity vector distribution of part of the sensor. It is clearly showed that an eddy was produced at the central cavity due to sudden change of sectional area, which causes the collision of airflow and sensor interior face. However, it can be seen in Figure 8 that the pressure loss is small because of small disturbance intensity. But the eddy will cause suspension of PM in this place and increase its stagnation time. And rate of exhaust gas is steady in the subsequent flowing space without eddy formed. Figure 10 shows the velocity vector distribution of $x=-25$ annular section. The outermost, intermediate, and innermost torus is velocity vector distribution of the flow space of outboard protective element, concentration testing area, and central cavity, respectively. At the windward side of the outermost torus, velocity of airflow is low, while it is high at the leeward side. It is mainly because of the block of flow guide, which decreases the momentum of gas at the windward side and generates acceleration area at the side of annular flow guide. The flow rate of concentration testing area is steady, which indicates that the flow space of outboard protective element can stabilize flow rate, and it makes contribution to the stabilization of PM flow rate in the concentration testing area.

3.2. Distribution Conditions of the PM. Figure 11 shows the distribution conditions of PM inside the sensor when exhaust flow rate is $72,55,37$ meter per second, respectively. By comparison, there is an obvious reduction of PM inside the maze structure design when exhaust flow rate is 55 and 37 meter per second. It indicates that maze structure design can prevent PM effectively when flow rate is low. However, there is more PM distributed in maze structure design at high flow rate because exhaust gas of high flow rate has a strong carrying effect on PM. A little PM is distributed at windward side of outboard protective element for the low flow rate there and it is more obvious with low flow rate. But when flow rate is high, distribution of PM inside the sensor is relatively homogeneous.

According to the relevant research, all sizes of PM distributed evenly and unorderly inside the sensor, but around the maze structure design, the amount of the PM tends to be less, and the size of the PM tends to be smaller. The maze structure reduces the PM concentration at the end space of the sensor and makes PM distribution of other parts homogeneous, which is advantageous to the accurateness of the sensor.

\section{Experiment}

Figure 12 shows the signal collection system, installation of sensors, test bench, and control circuits. Feasibility study of the sensor to measure PM concentration was performed. 186FA single-cylinder air cooled diesel engine was used in the first round bench test. An electric eddy current dynamometer and a smokemeter are used in the test, which are produced 

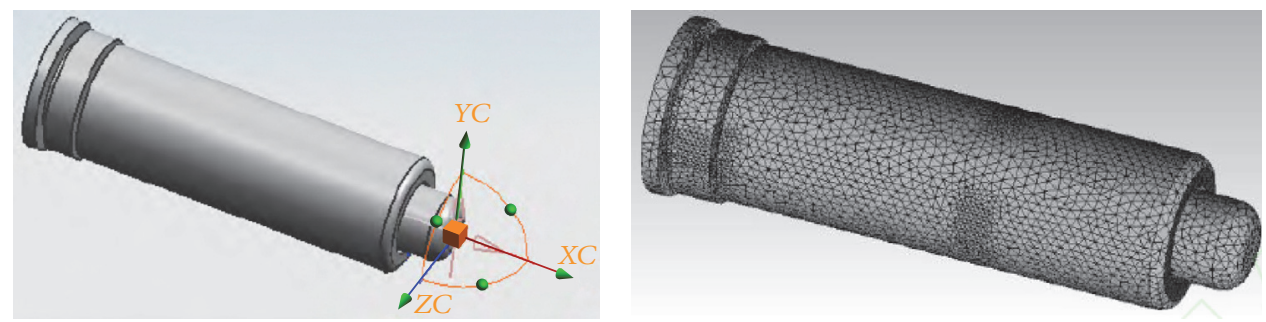

Figure 6: Three-dimension and mesh model of the PM sensor.

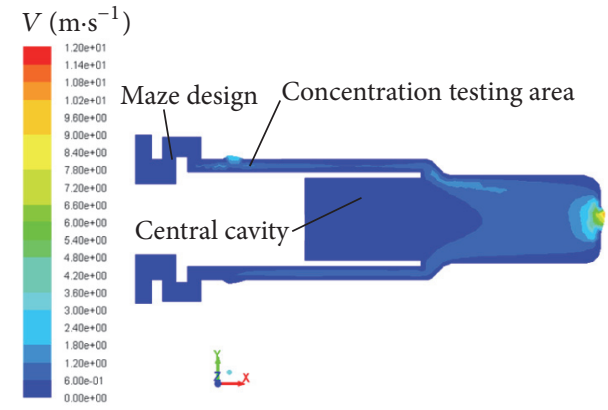

FIGURE 7: The velocity distribution of $z=0$ section.

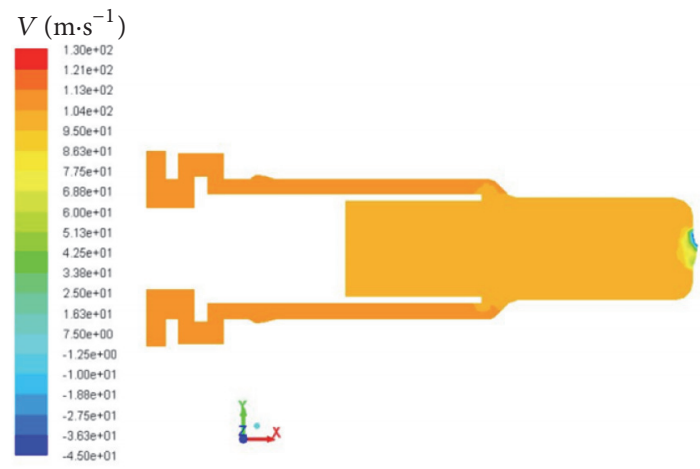

FIGURE 8: Static pressure distribution of $z=0$ section.

by Hangzhou Zhong Cheng Testing Technology Ltd. and Wenzhou Instrument Factory of China, respectively, and the data collection system is self-made.

4.1. Output Voltage at Different Testing Condition. The PM concentration is different under different testing conditions. And smoke intensity increases with the enhancement of load, as well as the PM concentration. Therefore, the load conditions of $10 \%, 50 \%$, and $100 \%$ at rated speed can be selected in the bench test and then the average data are collected each time. When the engine load runs at full load, the working condition can be very tough because of the high velocity of the exhaust gas flow and high temperature. The stability of the sensor can be guaranteed if it still works well under full load. From the results in Table 2 and Figures 13 and 14, it can be seen that the output voltage increases with the increasing engine load (as well as the smoke intensity and

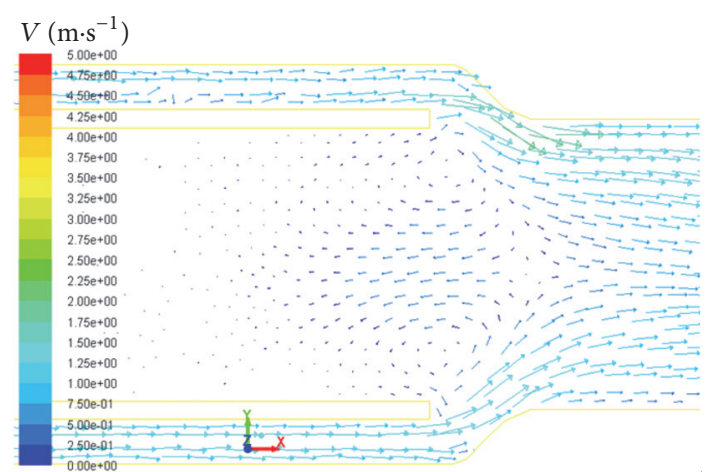

FIGURE 9: The local velocity vector distribution.

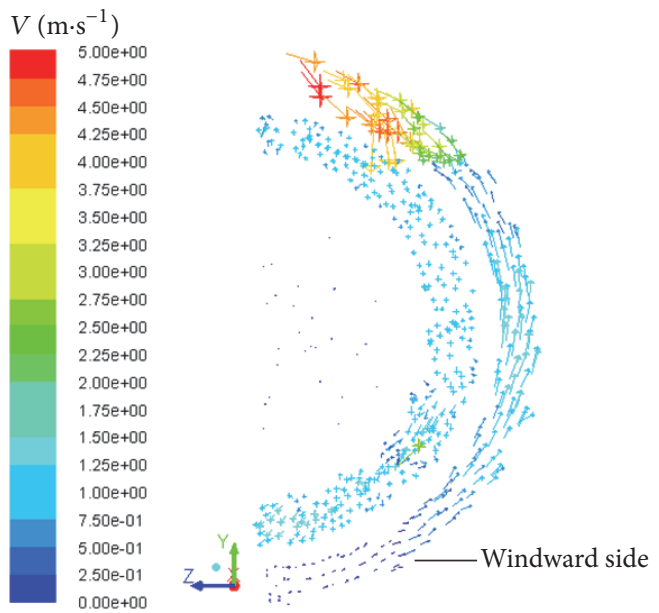

FIGURE 10: The velocity vector distribution of $x=25$ ring section.

PM concentration). It reveals the feasibility of the sensor to measure PM concentration.

\subsection{Influence of Exhaust Gas Temperature upon Sensor} Output. For a leakage current PM sensor like this, changes in measured values have two possibilities: that the PM concentration has changed or that the PM concentration has not changed, but conditions have changed. In this paper, we study the influence of exhaust gas temperature upon sensor output. The schematic of artificial test bench can be seen in Figure 15. Concentration and temperature are controlled by the mass flow controller and heater separately. We measure the sensor output under different temperatures with the same 
TABLE 2: Output signal in different loads.

\begin{tabular}{lccc}
\hline Load & Average collected in the first time $(\mathrm{V})$ & Average collected in the second time $(\mathrm{V})$ & Average collected in the third time $(\mathrm{V})$ \\
\hline $10 \%$ & 0.78 & 0.72 & 0.83 \\
$50 \%$ & 2.43 & 2.47 & 2.46 \\
$100 \%$ & 4.13 & 4.14 & 4.16 \\
\hline
\end{tabular}

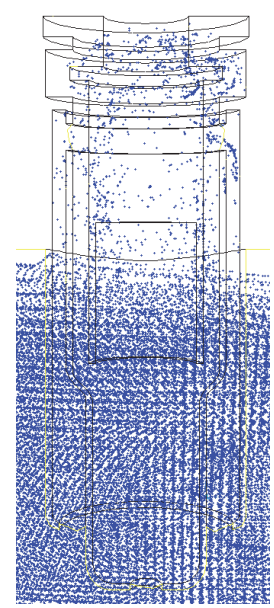

(a)

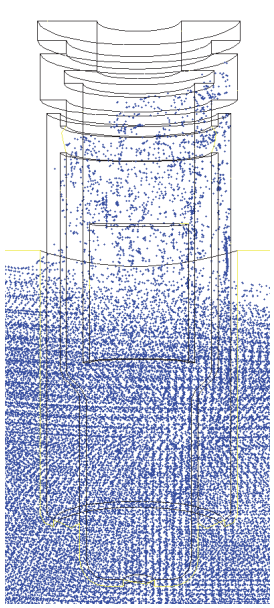

(b)

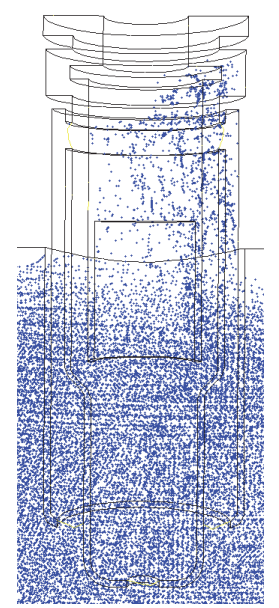

(c)

FIGURE 11: Particulate distribution inside the sensor.
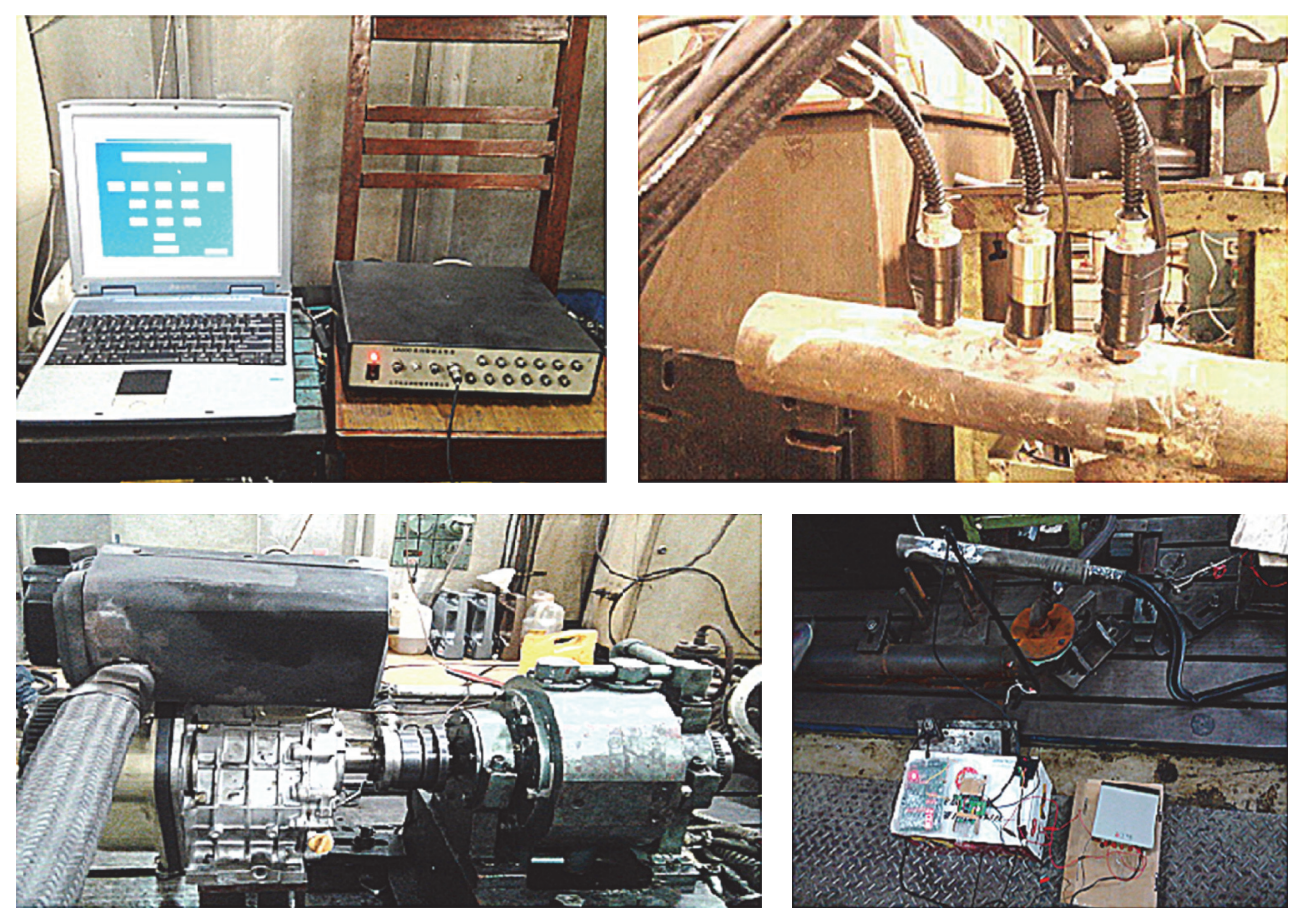

Figure 12: Different parts of bench test.

change of PM concentration. Normalized sensitivity was calculated under different temperatures, which can be seen in Figure 16, the change sensor output is strongly influenced by EGT, and sensitivity changes by 3 times over temperature range from $240^{\circ} \mathrm{C}$ to $473^{\circ} \mathrm{C}$. A ceramic heater can reduce the influence to the output signal during the heating procedure and burn off the carbon bridge caused by PM concentration. To ensure that the sensor is accurate enough to fulfill its task, 


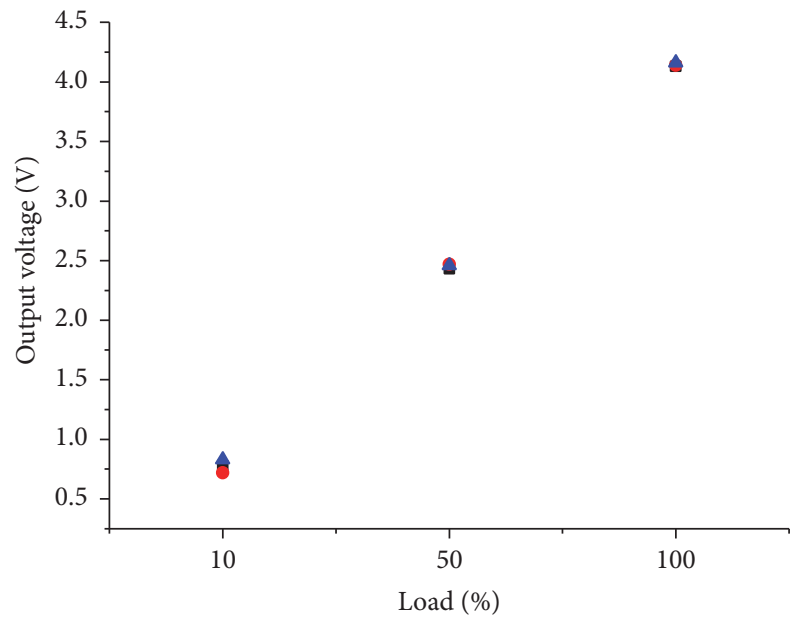

- Average collected in the first time

- Average collected in the second time

- Average collected in the third time

FIGURE 13: Output signal diagram in different loads.

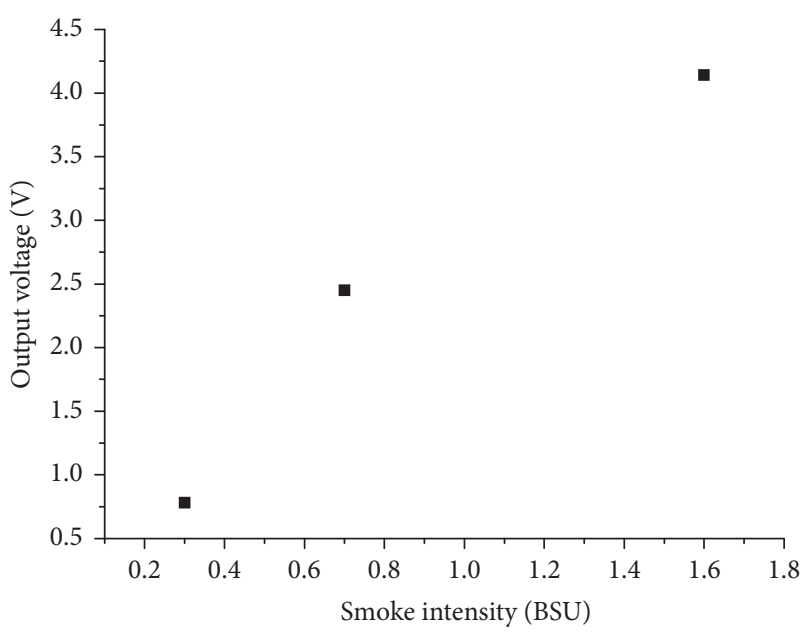

FIGURE 14: Output signal in different smoke intensity.

a controlled and interrupted heating processing should also be adopted. And a universal temperature correction should be applied to sensor output.

\section{Conclusion}

In this paper, the structure and principle of the PM sensor are introduced. The gas-solid two-phase flow numerical simulation is carried out, and simulation analysis was applied to the design of Venturi tube and maze structure design. Finally bench test was performed for a feasibility study of PM concentration detection and study of the influence of EGT upon sensor output.

The conclusions obtained can be seen as follows:

(1) The design of Venturi tube in the sensor produces differential pressure and has a significant effect on stability of the internal air flow.

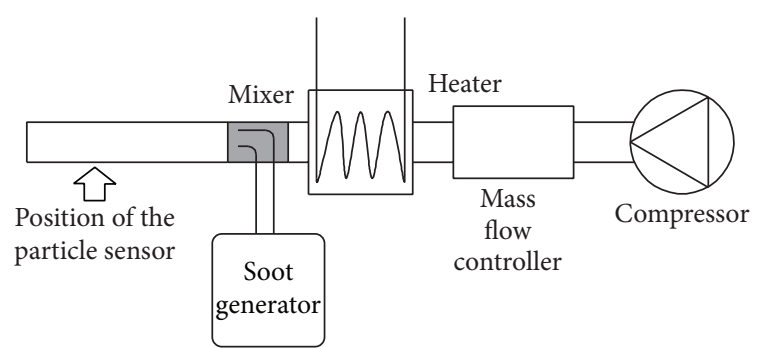

FIGURE 15: Schematic set-up of the artificial soot particle test bench.

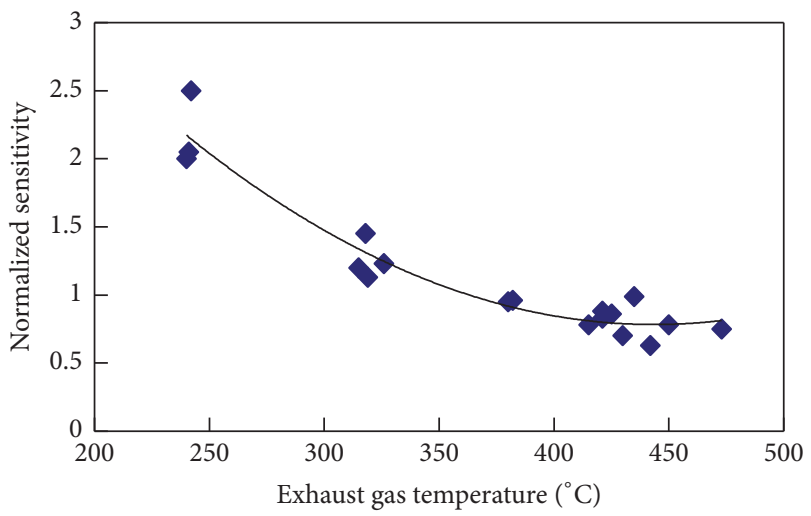

FIGURE 16: Sensitivity over different exhaust gas temperature.

(2) The maze design can prevent the PM from entering into sealed space effectively at low flow rate.

(3) The output signal increases with the increasing engine load, which confirms the feasibility of PM concentration detection of the leakage current PM sensor.

(4) The sensor output is strongly influenced by EGT so universal temperature correction should be applied to sensor output.

But this is a fundamental study of the new PM sensor; a further study should be performed for commercial application. Thermal analysis based on finite element method needs to be taken. By establishing 3D model and carrying out numerical simulation, the transient and steady state of temperature fields of the sensor can be approached. The appropriate heating power of the sensor which can guarantee the quick and safe turning of the sensor into its response phase can be reached by studying the temperature fields and transient simulations under different heating power.

\section{Additional Points}

A new sensor for transient PM (discharged by diesel engine) concentration measurement was used.

\section{Competing Interests}

The authors declare that they have no financial and personal relationships with other people or organizations that can inappropriately influence their work; there is no professional 
or other personal interests of any nature or kind in any product, service, and/or company that could be construed as influencing the position presented in, or the review of, the manuscript entitled.

\section{Acknowledgments}

This work was financially supported by the Priority Academic Program Development (PAPD) in China, the Project of International Cooperation (no. BZ2012025) in Jiangsu Province of China, the 2016 Priority Research Project (BE2016141) in Jiangsu Province of China, the 2016 Postgraduate Innovation Program in Jiangsu Province of China, and the Project of State Key Laboratory of Internal Combustion Engines (no. K20149) in Tianjin University of China.

\section{References}

[1] H. S. Rosenkranz, "Mutagenic nitroarenes, diesel emissions, particulate-induced mutations and cancer: an essay on cancercausation by a moving target," Mutation Research-Genetic Toxicology, vol. 367, no. 2, pp. 65-72, 1996.

[2] J. G. M. Brandin, L. A. H. Andersson, and C. U. I. Odenbrand, "Catalytic reduction of nitrogen oxides on mordenite some aspect on the mechanism," Catalysis Today, vol. 4, no. 2, pp. 187203, 1989.

[3] L. Huang, S. V. Bohac, S. M. Chernyak, and S. A. Batterman, "Effects of fuels, engine load and exhaust after-treatment on diesel engine SVOC emissions and development of SVOC profiles for receptor modeling," Atmospheric Environment, vol. 102, pp. 228-238, 2015.

[4] J. R. Serrano, H. Climent, P. Piqueras, and E. Angiolini, "Analysis of fluid-dynamic guidelines in diesel particulate filter sizing for fuel consumption reduction in post-turbo and preturbo placement," Applied Energy, vol. 132, pp. 507-523, 2014.

[5] K. Oravisjärvi, M. Pietikäinen, J. Ruuskanen et al., "Diesel particle composition after exhaust after-treatment of an off-road diesel engine and modeling of deposition into the human lung," Journal of Aerosol Science, vol. 69, pp. 32-47, 2014.

[6] Y. Shen, T. Takeuchi, S. Teranishi, and T. Hibino, "Alumina substrate-supported electrochemical device for potential application as a diesel particulate matter sensor," Sensors and Actuators, B: Chemical, vol. 145, no. 2, pp. 708-712, 2010.

[7] T. Nakata, H. Akita, K. Saguchi, and K. Kunimatsu, CO gas sensor, JP Patent 2,001,041,925.

[8] H. Scheer, H. J. Renz, S. Roesch, H. Koehnlein, B. Gaertner, and I. Gerner, "Sensor element for a particle sensor," DE Patent $102,006,032,741$.

[9] C.-B. Lim, H. Einaga, Y. Sadaoka, and Y. Teraoka, "Preliminary study on catalytic combustion-type sensor for the detection of diesel particulate matter," Sensors and Actuators B: Chemical, vol. 160, no. 1, pp. 463-470, 2011.

[10] T. Ochs and H. Schittenhelm, Particulate Matter Sensor for on Board Diagnostics (OBD) of Diesel Particulate Filters (DPF), SAE International, 2010.

[11] A. Kondo, S. Yokoi, T. Sakurai et al., "New particulate matter sensor for on-board diagnostics," Aachener Kolloquium Fahrzeug-und Motorentechnik, vol. 19, pp. 405-415, 2010.

[12] L. Cheng, X. J. Zhong, T. W. Xing et al., A Particulate Matter Sensor and its Measuring Method, 2012.
[13] N. Li, D. Tang, and L. Cheng, "Research on new particulate matter sensor for diesel on-board diagnostics," Instrument Technique and Sensor, no. 6, pp. 1-3, 2013.

[14] A. Kondo, T. Sakuma, T. Sakurai, and T. Egami, New Particulate Matter Sensor for On-Board Diagnostics, Aachener Kolloquium Fahrzeugund Motorentechnik, Aachen, Germany, 2010.

[15] W. Manfred, R. Christian, and L. Thomas, Particulate Filter Onboard Diagnostics by Means of a Particle Sensor, FISITA, Munich, Germany, 2010.

[16] K. W. Chu, B. Wang, A. B. Yu, and A. Vince, "CFD-DEM modelling of multiphase flow in dense medium cyclones," Powder Technology, vol. 193, no. 3, pp. 235-247, 2009.

[17] D. Tang, Y. Z. Wu, N. Li, L. Cheng, Z. X. Liu, and Y. C. Xu, "Simulation of gas-solid two-phase flow of particulate matter sensor for diesel engine," Chinese Internal Combustion Engine Engineering, no. 3, pp. 147-151, 2015.

[18] Y.-Y. Bu, X.-K. Kang, and S. Wu, "Simulation of the gassolid turbulent flow of centrifugal radial-straight-blade wet fan," Journal of Zhengzhou University (Engineering Science), vol. 32, no. 4, pp. 76-80, 2011.

[19] X. Chen, W. Zhong, B. Sun, B. Jin, and X. Zhou, "Study on gas/solid flow in an obstructed pulmonary airway with transient flow based on CFD-DPM approach," Powder Technology, vol. 217, pp. 252-260, 2012.

[20] Y. Nong, "Research and design on networked auto sensor based on CAN bus," Transducer and Microsystem Technologies, vol. 26, no. 8, p. 90, 2007.

[21] L. Cheng, X. J. Zhong, T. W. Xing et al., "A High Precise Particulate Matter Sensor," China, CN202611820 U, 2012. 


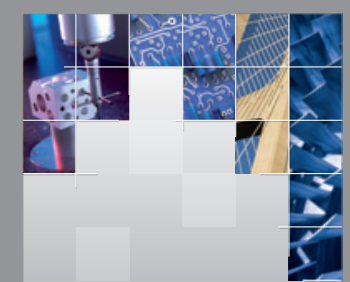

\section{Enfincering}
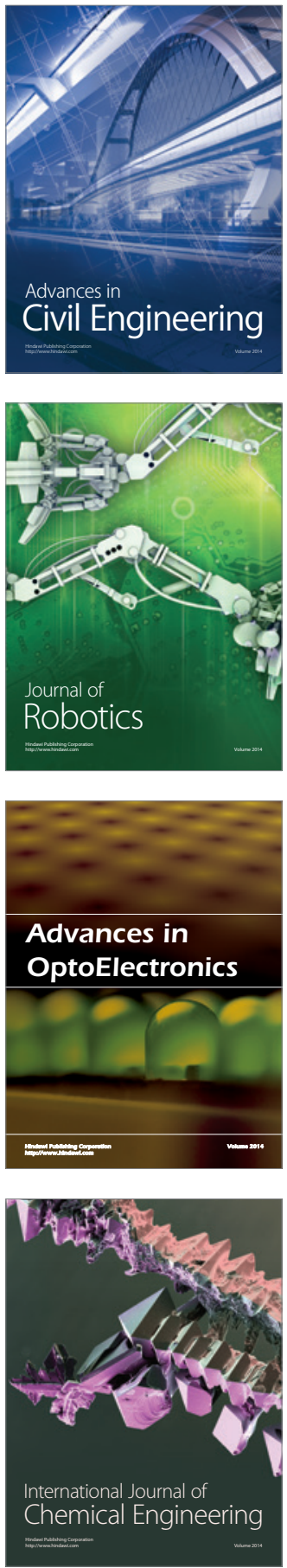

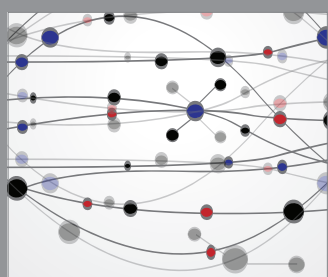

The Scientific World Journal

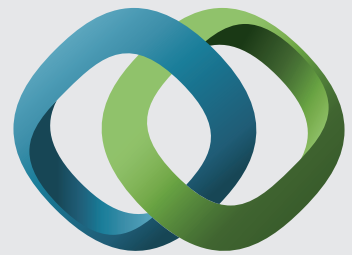

\section{Hindawi}

Submit your manuscripts at

http://www.hindawi.com
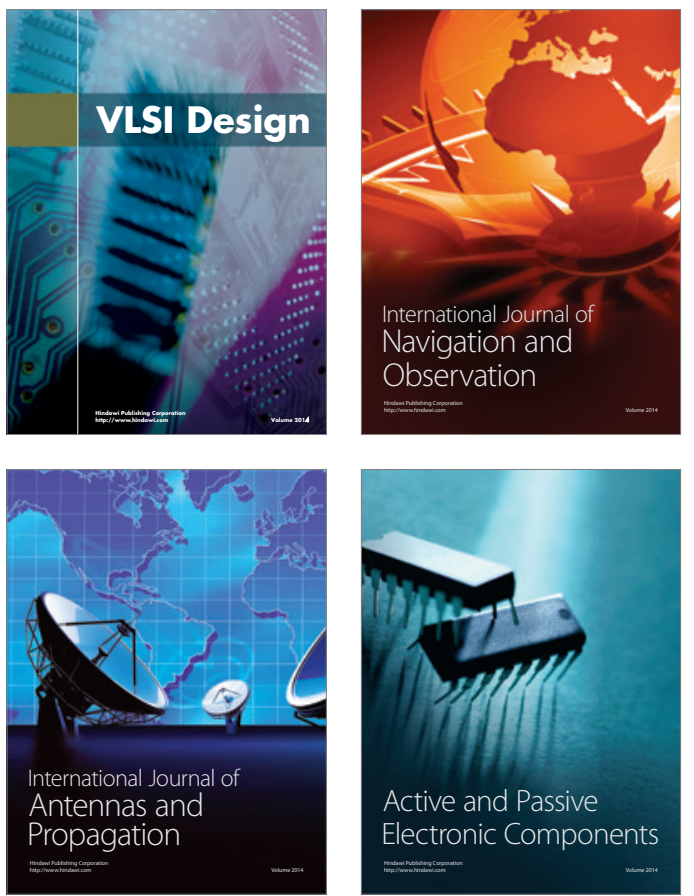
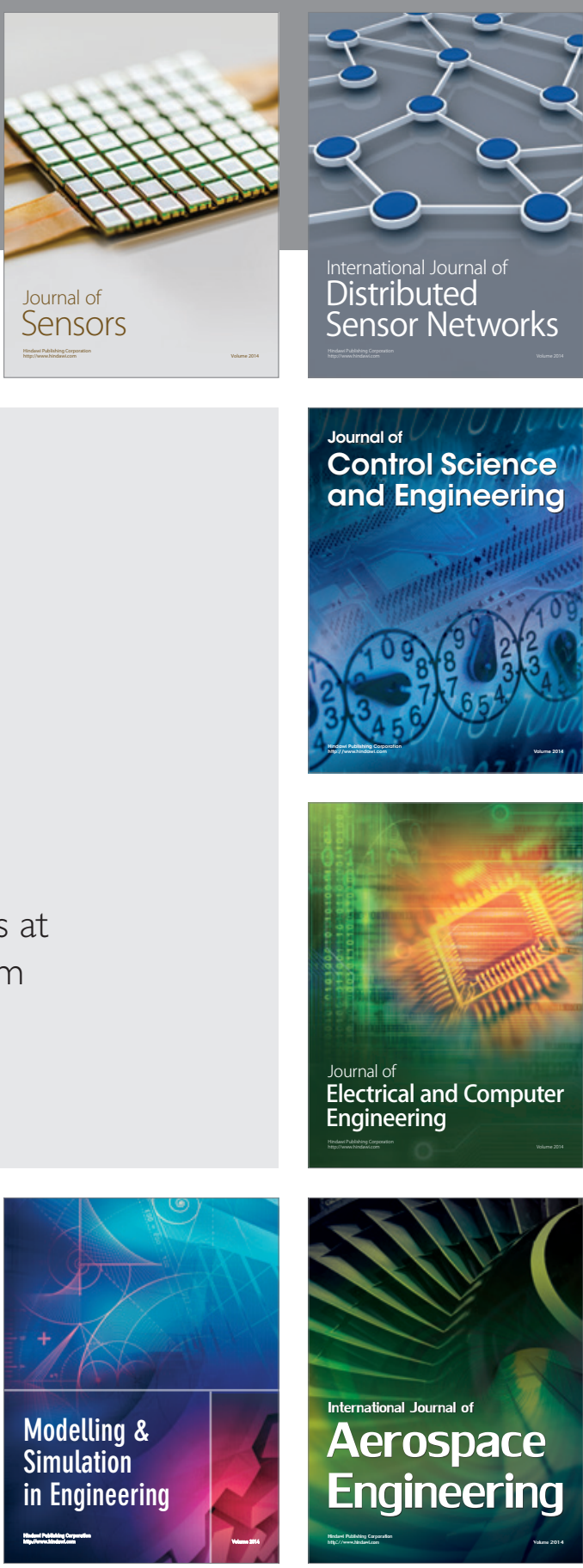

International Journal of

Distributed

Sensor Networks

Journal of

Control Science

and Engineering
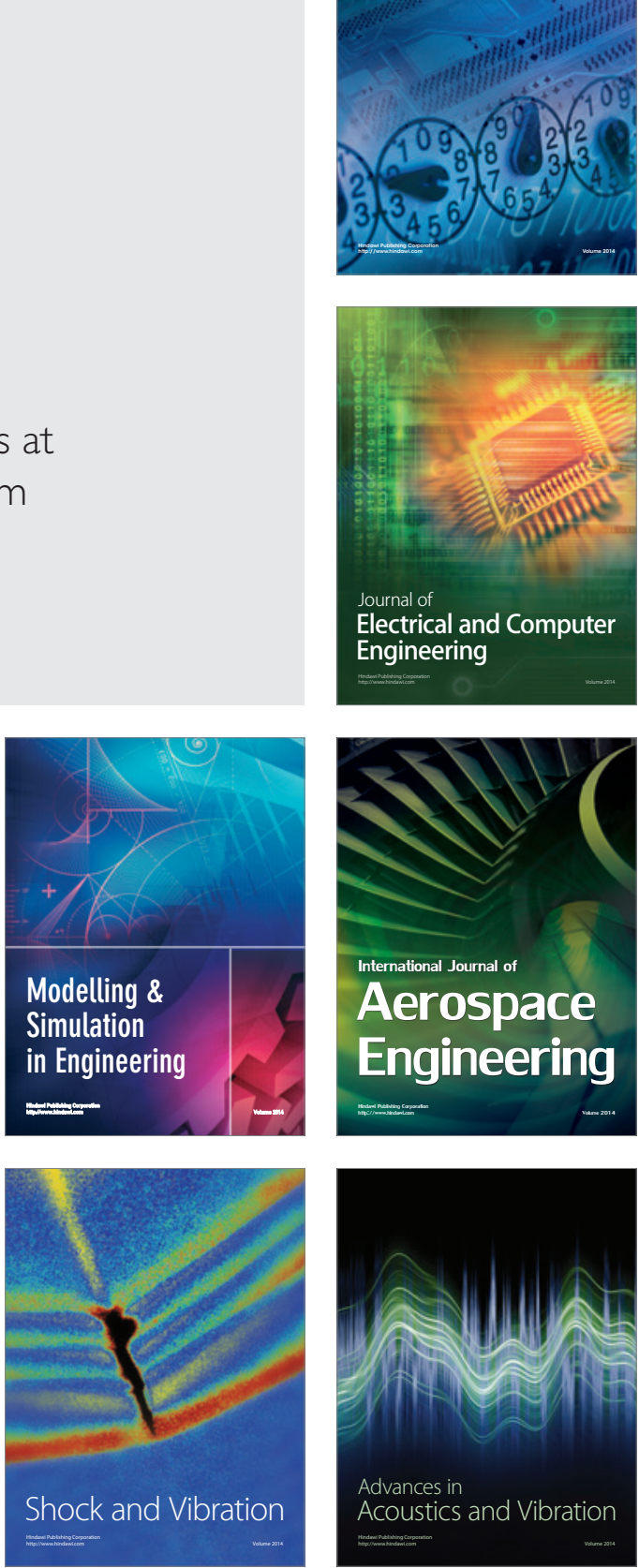